\title{
CAUSAS DE NÃO RECEBIMENTO DO LEITE CRU REFRIGERADO EM USINA DE BENEFICIAMENTO DO AGRESTE MERIDIONAL DE PERNAMBUCO
}

\section{Causes of non-receipt of refrigerated raw milk in a dairy industry in the Pernambuco's meridional "Agreste" region}

\author{
Ana Erundina de Luna Moraes Leite ${ }^{I^{*}}$, Marcelo Mendonça ${ }^{1}$, Karla Sequeira Mendonça ${ }^{2}$, \\ Marcos Pinheiro Franque ${ }^{l}$
}

\section{RESUMO}

O leite possui constituintes de grande valor nutricional e sua produção e consumo têm crescido a cada ano mundialmente. Associado à sua importância econômica, este produto é constantemente alvo de fraudes e adulterações, as quais trazem como consequência grandes prejuízos à indústria e preocupação aos órgãos de saúde pública. Neste sentido, objetivamos analisar, de forma retrospectiva, as causas que determinaram o não recebimento do leite cru refrigerado em usina de beneficiamento sob Inspeção Federal, da região do Agreste Meridional de Pernambuco, durante o período que compreendem os meses de março a outubro de 2016, com base no arquivo de registros da empresa. Foram identificados 122 casos de não recebimento de leite cru refrigerado. Destes, a principal causa foi a adição de água (34,5\%), seguida por acidez acima do limite estabelecido pela empresa, máximo $0,16 \mathrm{~g}$ de ácido lático/100 $\mathrm{mL}$ de leite $(30,3 \%)$, e presença de resíduos de antibióticos no leite $(26,2 \%)$. Desta forma, reforçou-se a importância do controle de qualidade e de identidade do leite realizado pela empresa, para evitar que um leite adulterado seja processado pela indústria e disponibilizado ao consumidor. Reforçou-se, também, a necessidade de aprimoramento da política leiteira, para fins de esclarecer, orientar e incentivar os produtores com relação a implementação das Boas Práticas Agropecuárias de produção do leite, incluindo a necessidade da realização de uma Ordenha Higiênica, do respeito do tempo de carência dos

1 Universidade Federal Rural de Pernambuco, Unidade Acadêmica de Garanhuns, Av. Bom Pastor, s/n, Boa Vista, 55292-270, Garanhuns, PE, Brasil. E-mail: anaerundina.moraes@gmail.com

2 Centro Universitário Maurício de Nassau, UNINASSAU, Garanhuns, PE, Brasil

* Autor para correspondência. 
antibióticos utilizados no tratamento dos animais e, principalmente, os prejuízos causados pela adição de substâncias fraudulentas.

Palavras-chave: fraude em leite; segurança alimentar; qualidade; inspeção.

\begin{abstract}
Milk has constituents of great nutritional value and its production and consumption have grown every year worldwide. Associated with its economic importance, this product is constantly the target of fraud and adulteration, which causes as a consequence great damages to the industry and concern to the public health organs. In this sense, we aimed to analyze, retrospectively, the causes that determined the non-receipt of the refrigerated raw milk in a dairy industry with Brazilian Federal Inspection, in the region of meridional "Agreste" of Pernambuco (Brazil), during the period that comprise the months of March to October 2016, based on files of the industry records. In this period, 122 cases of non-receipt of refrigerated raw milk by the industry were identified. Of these, the main cause was water addition $(34.5 \%)$, followed by milk with acidity above the limit established by the industry, maximum $0.16 \mathrm{~g}$ of lactic acid/100 $\mathrm{mL}$ of milk $(30.3 \%)$, and presence of antibiotic residues in milk $(26.2 \%)$. Thus, the importance of quality and identity control of the milk performed by the company was reinforced, to prevent the industry from processing adulterated milk that will be later made available to the consumer. The need to improve milk policy was also reinforced for the purpose of educating, guiding and encouraging producers regarding the implementation of Good Agricultural Practices for milk production, including the need for a Hygienic Milking, respect for antibiotic withdrawal period, when it is used used in animal treatment and, especially, the damage caused by the addition of fraudulent substances to the milk.
\end{abstract}

Keywords: milk fraud; food safety; quality; inspection.

\section{INTRODUÇÃO}

A ingestão de alimentos nutritivos, incluindo o leite, capazes de fornecer ao consumidor elementos essenciais é imprescindível para o funcionamento pleno do organismo. Altamente consumido no Brasil e no mundo, o leite apresenta alto valor nutricional pela presença de componentes importantes para a dieta humana, principalmente, para crianças e idosos (FAO, 2019a). Entende-se por leite, sem outra especificação, o produto oriundo da ordenha completa e ininterrupta, em condições de higiene, de vacas sadias, bem alimentadas e descansadas (BRASIL, 2017).

A produção de leite é crescente a cada ano. Em 2018 a produção mundial total de leite foi estimada em 843 milhões de toneladas, um aumento de $2,2 \%$ em relação a 2017. Neste cenário, o Brasil ocupa a quinta posição na produção mundial de leite, com uma produção de 35.539 mil toneladas, uma taxa de aumento de $0,8 \%$ quando comparada com 2017 (FAO, 2019b). Embora não esteja entre as regiões de maior produção leiteira do Brasil, o estado de Pernambuco, onde predominam produtores familiares com baixo grau de tecnificação, apresentou uma produção de 241.257 mil litros de leite cru, resfriado ou não, em consequência ocupa a $14^{\text {a }}$ posição no ranking nacional em 2018 (IBGE, 2019). 
A economia do Agreste Meridional Pernambucano tem na pecuária leiteira sua principal base, sendo a região conhecida como a Bacia Leiteira do estado, com participação de mais de $20 \%$ da produção total de leite de Pernambuco (PE-AZ, 2016).

Do ponto de vista físico-químico, o leite é uma mistura homogênea de substâncias incluindo lactose, glicerídeos, proteínas, sais, vitaminas e enzimas, das quais algumas estão em emulsão (gordura), algumas em suspensão (as caseínas ligadas a sais minerais) e outras em dissolução verdadeira (lactose, vitaminas hidrossolúveis, proteínas do soro, sais) (BELOTI et al., 2015). Sua composição é complexa e pode apresentar variação de acordo com a raça, alimentação, idade e número de parições, tempo de lactação e variações climáticas (ABRANTES et al., 2014).

Tendo em vista que o leite é um produto de origem animal (POA) bastante consumido e um grande fomentador do agronegócio brasileiro, este produto continua sendo alvo de fraudes e adulterações. Tal situação representa risco à saúde do consumidor, constituindo uma preocupação à saúde pública além de causar prejuízos econômicos ao setor (SILVA, 2013). Existem vários tipos de fraudes, todas visando maior lucratividade, seja pelo aumento de volume do leite (fraude por aguagem associada à adição de reconstituintes de densidade) ou, para prolongar a vida útil de um produto de baixa qualidade microbiológica (fraude por adição de conservantes ou neutralizantes) (BELOTI et al., 2015).

A legislação vigente preconiza o controle diário da identidade e da qualidade do leite cru refrigerado para cada compartimento do caminhão tanque, quando do seu recebimento no estabelecimento beneficiador. Para tanto, são realizadas várias análises do leite, tais como: temperatura, teste do Álcool/Alizarol, acidez titulável, índice crioscópico, densidade relativa, pesquisa de substâncias neutralizantes da acidez e de reconstituintes da densidade, pesquisa de agentes inibidores do crescimento microbiano, dentre outras (BRASIL, 2018).

Considerando os desafios para se produzir leite na região Agreste Meridional de Pernambuco, as indústrias vivenciam constantes problemas na captação de leite cru refrigerado em quantidade e qualidade desejáveis. Desta forma, o nosso objetivo foi identificar as causas de não recebimento do leite cru refrigerado em uma Usina de Beneficiamento sob Inspeção Federal, localizada na região do Agreste Meridional de Pernambuco, durante o período de março a outubro de 2016.

\section{MATERIAL E MÉTODOS}

Selecionou-se para estudo uma indústria de destaque no desenvolvimento da cadeia leiteira da região. Desta forma, o estudo foi realizado em uma Usina de Beneficiamento de leite fiscalizada por profissionais do Serviço de Inspeção Federal (SIF), instalada na cidade da Pedra, no Agreste Meridional do estado de Pernambuco, com captação média de 170 mil litros de leite/dia, produzidos nos municípios de Pedra e circunvizinhos a qual comercializava leite UHT - Ultra High Temperature, leite pasteurizado e leite condensado em toda a região Nordeste do país.

O diagnóstico sobre as causas de não recebimento do leite cru refrigerado na usina de beneficiamento foi realizado por meio do acesso aos registros da empresa e a construção de um banco de dados referente ao período de março a outubro de 2016, seja para ao leite oriundo de tanques de expansão direta individual ou comunitário, captado pela empresa em caminhões tanques. A indústria utilizava os critérios de identidade e qualidade do leite cru refrigerado estabelecidos na Instrução Normativa (IN) $n^{\circ} 62$ de 2011 (BRASIL, 2011), exceto para acidez titulável, para o qual a empresa adotava um critério 
mais rigoroso de até $0,16 \mathrm{~g}$ de ácido lático/ $100 \mathrm{~mL}$ de leite, e os métodos analíticos oficiais físico-químicos descritos na $\mathrm{IN} \mathrm{n}^{\circ} 68$ de 2006 (BRASIL, 2006), ambas do Ministério da Agricultura, Pecuária e Abastecimento e vigentes à época da realização do estudo. Os dados foram analisados por meio de estatística descritiva.

\section{RESULTADOS E DISCUSSÃO}

Constatou-se, entre março e outubro de 2016, registros de 122 casos de não recebimento de leite cru refrigerado na Usina de Beneficiamento, sendo a principal causa fraude por aguagem do leite em $34,5 \%$ das amostras (42/122), verificada por meio da determinação do índice crioscópico, em desacordo com o padrão estabelecido na legislação (>-0,530 ${ }^{\circ} \mathrm{H}-\mathrm{IN} \mathrm{n}^{\circ} 62$ de 2011, vigente à época do estudo, e RIISPOA, 2017, vigente atualmente). A segunda causa principal foi a acidez titulável do leite acima do limite estabelecido pela empresa (máx. $0,16 \mathrm{~g}$ de ácido lático/100 mL) com 30,3\% das amostras em desacordo (37/122), seguida pela presença de resíduos de antibióticos (ATB) com 26,2\% (32/122) das amostras em desacordo. As demais causas foram: leite alcalino $(<0,14 \mathrm{~g}$ de ácido lático/100 mL) em $3,3 \%(4 / 122)$ e leite com índice crioscópico inferior ao preconizado pela legislação, ou seja, menor do que $-0,555^{\circ} \mathrm{H}$ (BRASIL, 2017; BRASIL, 2018) em 1,6\% das amostras (2/122). Em alguns casos foram detectadas mais de uma causa para o não recebimento do leite cru refrigerado incluindo acidez titulável acima de 0,16 g de ácido lático/ $100 \mathrm{~mL}$ em 2,5\% das amostras (03/122), associada ao índice crioscópico inferior à $-0,555^{\circ} \mathrm{H}$; presença de resíduos de antibiótico em $0,8 \%$ das amostras (01/122) associado a acidez titulável acima de 0,16 g de ácido lático/100 mL; e alcalinidade do leite em $0,8 \%$ das amostras (01/122), associada à presença de substâncias alcalinas, neutralizantes de acidez (Tabela 1).

Valores de índice crioscópico em desacordo com a o padrão legal, entre $-0,530{ }^{\circ} \mathrm{H}$ a $-0,555^{\circ} \mathrm{H}$, são indicativos de fraude por adição de água ao leite a qual, em geral, é associada à fraude por adição de substâncias reconstituintes da densidade do leite. Essas fraudes são praticadas, criminosamente, por produtores com a intenção de obter um maior volume de leite e alcançar maior lucratividade (BELOTI et al., 2015).

Os resultados do nosso estudo, por meio do qual se identificaram fraude por aguagem em $34,5 \%$ dos casos de não recebimento de leite cru (42/122) são reforçados por outros estudos. Trindade et al. (2018) verificaram índice crioscópico acima do parâmetro legal em quatro de cinco amostras de leite cru comercializadas de forma irregular em cinco comércios do município de Rio Pomba (MG); Mendes et al. (2010) detectaram índice crioscópico em desacordo como limite legal em $50 \%$ das amostras de leite in natura, comercializados, informalmente, no município de Mossoró (RN). Beloti et al. (2011) detectaram 18,2\% das amostras de leite cru refrigerado, produzido no município de Sapopema (PR) em desacordo com a exigência legal; Freitas Filho et al. (2009), identificaram fraude por aguagem em 4 amostras de leite in natura, comercializados informalmente, no município de Garanhuns (PE); Dutra (2010) detectou fraude por aguagem em 16,98\% (9/53) das amostras de leite cru refrigerado provenientes de uma indústria de laticínios do município de São Bento do Uma (PE) e Silva et al. (2016) constataram a fraude por adição de água no leite em 9,88\% (390,97 L) do volume avaliado, de um leite recebido por uma empresa de laticínios localizada no município de Conceição do Araguaia (PA). 


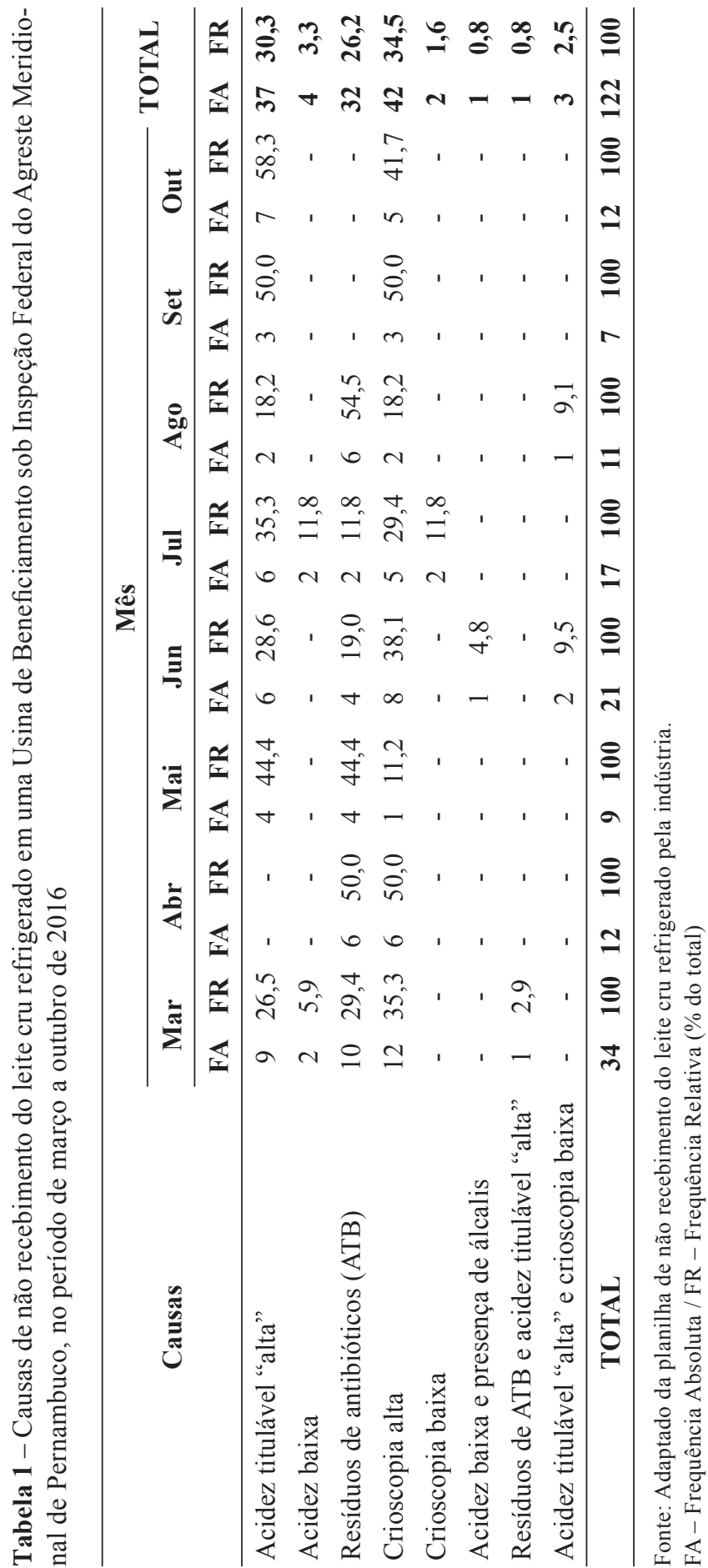


Embora a fraude pela adição de água tenha sido a principal causa do não recebimen to do leite pela Usina de Beneficiamento, não foi identificado fraude por adição de substâncias reconstituintes da densidade, as quais são praticadas para mascarar a adição de água ao leite. Entretanto, 1,6\% (02/122) dos casos de não recebimento do leite apresentaram índice crioscópico inferior a $-0,555^{\circ} \mathrm{H}$, resultado sugestivo da adição de água e de substâncias reconstituintes da densidade de forma excessiva, não detectada por meio das análises realizadas. É importante salientar que em outros estudos foram detectados além de fraude por adição de água ao leite, fraude por adição de substâncias reconstituintes como sacarose, cloretos, amido e urina (FREITAS FILHO et al., 2009; FIRMINO et al., 2010; COSTA et al., 2013; TRINDADE et al., 2018). Em estudo realizado por Firmino et al. (2010) também foi observado que em uma amostra de leite cru armazenado em tanques de expansão, a densidade e o índice crioscópico apresentaram valores em desacordo com a legislação, $1,028 \mathrm{~g} / \mathrm{L}$ para densidade e $-0,555^{\circ} \mathrm{H}$ para o índice crioscópico (BRASIL, 2018).

É importante salientar que em apenas cinco (05) amostras (4,1\%) de leite cru foram identificadas com acidez titulável menor do que 0,14 g ácido lático/100 mL (BRASIL, 2017; BRASIL, 2018), sendo que uma delas continham substâncias neutralizantes de acidez. Diante do total de casos de não recebimento, estas não representaram um número tão representativo. No entanto, este é um problema importante, uma vez que a adição de substâncias neutralizantes de acidez tem o intuito de mascarar a acidez promovida pelos microrganismos.

$\mathrm{O}$ alto percentual de ácido lático no leite torna este produto ácido, associado ao metabolismo das bactérias ácido-láticas que se multiplicam, devido, principalmente, a práticas ineficientes de higiene durante a ordenha, transporte e armazenamento do leite. Sabe-se que a acidez é também um fator limitante para o desenvolvimento de mais bactérias, quando o leite apresenta um alto índice de acidez. Ao adicionar substâncias neutralizantes, neutraliza-se a acidez, o que favorece o aumento da população microbiana (BELOTI et al., 2015). No entanto, a presença dessas substâncias neutralizantes pode ocorrer também em função da ocorrência de falhas de higienização de equipamentos e utensílios, ambientes com soluções alcalinas destinadas a remoção de gordura do leite, não sendo, diretamente, uma fraude intencional (ABRANTES et al., 2014). Considerando que a legislação determina um valor máximo de $0,18 \mathrm{~g}$ de ácido láctico/100 mL (BRASIL, 2017; BRASIL, 2018) pode-se afirmar que as amostras de leite apresentaram-se de acordo com o padrão legal. Dutra (2010) verificou uma alta acidez titulável em 94,9\% das amostras de leite cru refrigerado no estudo realizado em outra indústria de leite e derivados, também da região do Agreste Meridional de Pernambuco a qual recebia também leite cru não refrigerado. Trindade et al. (2018) também verificaram acidez acima do legal em quatro de cinco de amostras de leite cru comercializadas no município de Rio Pomba (MG). A acidez do leite é uma característica importante de qualidade indicativa das condições de produção e conservação. A manutenção do leite à temperatura ambiente favorece a multiplicação microbiana e a produção de ácido lático em decorrência da degradação da lactose. A acidificação do leite também pode ser associada à presença de colostro ou de grande quantidade de gás carbônico em animais com acidez metabólica (BELOTI et al., 2015). A alta acidez titulável e o baixo índice crioscópico constatados em três (03) amostras de leite $(2,5 \%)$ podem ser associadas à degradação microbiana da molécula de lactose com a produção de quatro moléculas de ácido 
lático. Este ácido permanece em solução e reduz o ponto de congelamento do leite. Assim, o índice crioscópico do leite inferior a $-0,555^{\circ} \mathrm{H}$ é indicativo de fraude ou de alta acidez (BELOTI et al., 2015).

Valor alto de acidez titulável, isolado ou associado à presença de resíduos de antibióticos ou índice crioscópico baixo, encontrado nas 41 amostras de leite cru refrigerado, foi um problema constante, na maioria dos meses, exceto em abril. Resíduos de antibióticos também foram detectados na maioria dos meses, exceto em setembro e outubro. É importante observar ainda, que a fraude por adição de água foi verificada em todos os meses (Figura 1). No entanto, é interessante ressaltar que esta Usina de Beneficiamento considera valores acima de $0,16 \mathrm{~g}$ de ácido lático/100 mL como altos. O fato de a indústria receber leite com acidez titulável máxima de $0,16 \mathrm{~g}$ de ácido lático/100 mL, a torna mais rigorosa frente a legislação vigente, cujo valor exigido é de, no máximo, 0,18 g de ácido lático/100 mL (BRASIL, 2017; BRASIL, 2018).

A detecção de resíduos de antimicrobianos, com um índice de 27,0\% (33/122) dos casos associados ao não recebimento do leite cru levantou também uma preocupação para a indústria. A Usina de Beneficiamento utiliza, como método de detecção de resíduos de antibióticos no leite, o kit IDEXX SNAP* Beta-Lactam ST (IDEXX Laboratories). Por meio deste kit podemse detectar resíduos de beta-lactâmicos em leite cru refrigerado, em apenas 6 minutos, o que permite testar amostras de leite coletadas diretamente do caminhão-tanque (IDEXX Laboratories, 2016). A ingestão de leite com resíduos de antibióticos consiste em problema de saúde pública, por poder acarretar transtornos à saúde do consumidor, como problemas de hipersensibilidade, resistência bacteriana, choque anafilático e efeitos tóxicos. Desordens ainda mais graves podem ocorrer quando o antibiótico utilizado

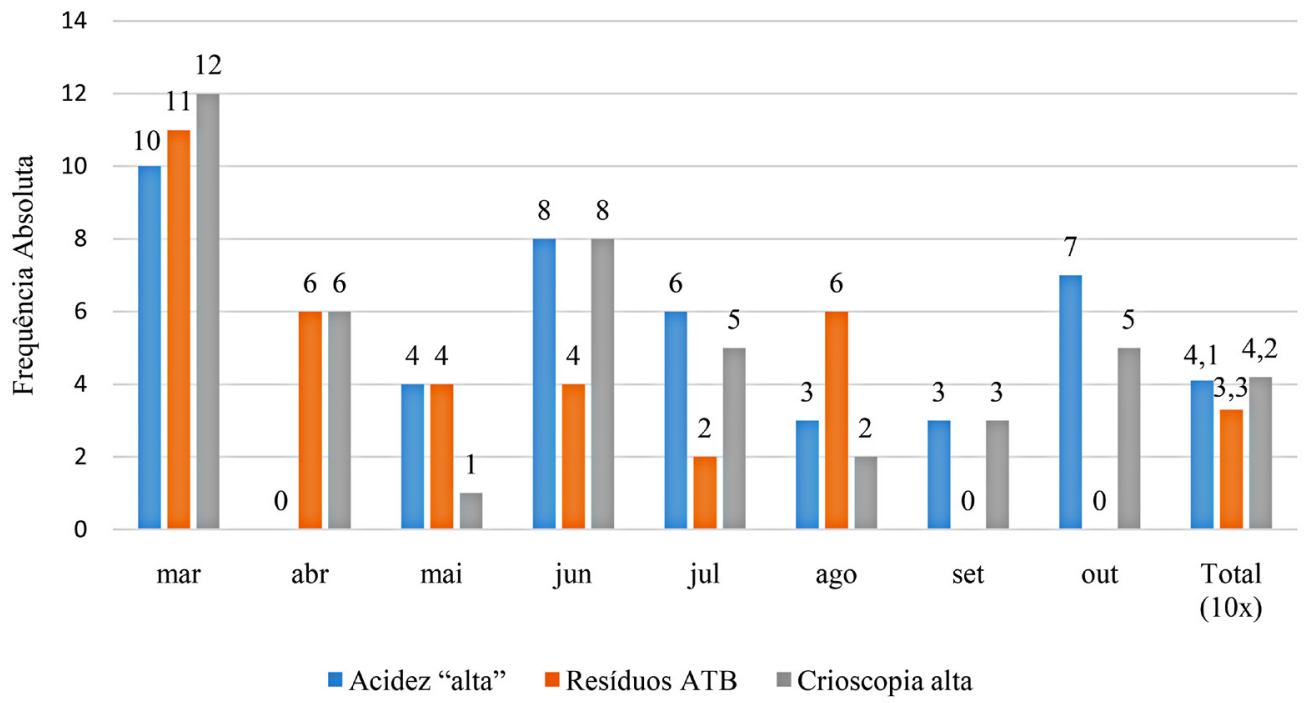

Figura 1 - Frequência Absoluta (FA) das principais causas de não recebimento do leite cru refrigerado em uma Usina de Beneficiamento, sob Inspeção Federal da mesorregião do Agreste Meridional, no período de março a outubro de 2016 
apresentar efeito teratogênico e seu resíduo for ingerido por gestantes, o que pode colocar em risco a saúde do feto, por exemplo, a ingestão de resíduos de nitrofuranos e tetraciclinas que podem levar a alterações no desenvolvimento ósseo do feto (BORGES et al., 2000; PEZZA et al., 2006; PEREIRA; SCUSSEL, 2017).

Em outros estudos também é relatada a presença de resíduos de antibióticos no leite. Souza et al. (2017) verificaram a presença de resíduos de antimicrobianos em 6 de $112(6,72 \%)$ amostras analisadas de leite bovino cru oriundas de produtores de seis municípios do estado do Rio Grande do Norte. Morais et al. (2010) constataram resíduos de antibióticos dentre 57 amostras de leite pasteurizado: 25 com presença de tetraciclinas (44\%), 2 com betalactâmicos (3,5\%), 4 com estreptomicina/diidroestreptomicina (7\%) e 6 com tetraciclinas e betalactâmicos $(10,5 \%)$. Cassoli et al. (2013) avaliaram amostras de leite coletadas em indústrias na região sudeste cujo sistema de pagamento considera a qualidade; os autores concluíram que dentre as 273.578 amostras analisadas, $2.483(0,91 \%)$ apresentaram-se contaminadas com resíduos de antibióticos. Costa et al. (2013) detectaram presença de resíduos de antibióticos em 0,22\% (15/6873) das amostras de leite cru refrigerado recebido por laticínios no município de São Luís de Montes Belos (GO). Além desses, Motta et al. (2013) em um estudo realizado com leite coletado em tanques de expansão individual (TI) e comunitário (TC) da região sudeste do estado de São Paulo, detectaram a presença de resíduos de antimicrobianos em $42 \%$ das amostras de leite dos TI e $35 \%$ dos TC.

Por fim, este estudo permitirá uma melhor compreensão das não conformidades do leite cru refrigerado produzido na região, bem como o direcionamento de ações preventivas e corretivas junto aos seus produtores fornecedores de leite, a fim de diminuir a frequência de casos de não conformidades do leite a ser captado.

\section{CONCLUSÕES}

De forma retrospectiva, as causas que determinaram o não recebimento do leite cru refrigerado em usina de beneficiamento sob Inspeção Federal, da região do Agreste Meridional de Pernambuco, durante o período de março e outubro de 2016, foram: fraude por aguagem, presença de resíduos de antibióticos e acidez titulável acima de 0,16 g de ácido lático/100 mL.

Assim, ações corretivas com o intuito de orientar e incentivar a implementação de Boas Práticas Agropecuárias, com ênfase na importância de uma ordenha higiênica, na obediência ao tempo de carência dos antibióticos e, principalmente, com relação a responsabilidade e prejuízos causados pela adição de substâncias estranhas ao leite, devem ser realizadas para minimizar perdas para o produtor e para a indústria. Destaca-se a importância da implementação de controles por parte do setor de inspeção e do controle de qualidade interno da empresa, considerando que são responsáveis pelas ações preventivas da adulteração do leite cru refrigerado e de promoção à saúde do consumidor.

\section{AGRADECIMENTOS}

Agradecemos à Usina de Beneficiamento pela confiança e pela disponibilidade para realização deste estudo.

\section{REFERÊNCIAS}

ABRANTES, M. R.; CAMPÊLO, C. S.; SILVA, J. B. A. Fraude em Leite: método de detecção e implicações para o consumidor. Revista Instituto Adolfo Lutz, v. 73, n. 3, p. 244-51, 2014. 
BELOTI, V. et al. Qualidade microbiológica e físico-química do leite cru refrigerado produzido no município de Sapopema/ PR. Revista Cientifica Eletrônica de Medicina Veterinária, ano 9, n.16, jan. 2011. Disponível em: http://faef.revista.inf. br/imagens_arquivos/arquivos_destaque/ gvRfHOQjI5PmOHd_2013-6-25-16-55-49. pdf. Acesso em: 29 mar. 2019

BELOTI, V. et al. Leite: obtenção, inspeção e qualidade. Londrina: Planta, 2015.

BORGES, G. T. et al. Ocorrência de resíduos de antibióticos em leite pasteurizado integral e padronizado produzido e comercializado no Estado de Goiás. Ciência Animal Brasileira, v.1, n.1, p.59-63, 2000.

BRASIL. Ministério da Agricultura Pecuária e Abastecimento. Departamento de Inspeção de Produtos de Origem Animal. Instrução Normativa $\mathrm{n}^{\circ}$ 68, de 12 de dezembro de 2006. Oficializa os Métodos Analíticos Oficiais Físico-Químicos, para Controle de Leite e Produtos Lácteos. Diário Oficial da União: seção 1, Brasília, DF, p. 8, 14 dez. 2006.

BRASIL. Ministério da Agricultura Pecuária e Abastecimento. Departamento de Inspeção de Produtos de Origem Animal. Instrução Normativa ${ }^{\circ}$ 62, de 29 de dezembro de 2011. Regulamento Técnico de Produção, Identidade e Qualidade do Leite tipo A, o Regulamento Técnico de Identidade e Qualidade de Leite Cru Refrigerado, o Regulamento Técnico de Identidade e Qualidade de Leite Pasteurizado e o Regulamento Técnico da Coleta de Leite Cru Refrigerado e seu Transporte a Granel. Diário Oficial da União: seção 1, Brasília, DF, p. 6, 30 dez. 2011.

BRASIL. Ministério da Agricultura Pecuária e Abastecimento. Departamento de Inspeção de Produtos de Origem Animal. Decreto $n^{\circ} 9.013$, de 29 de março de 2017. Regulamen- to de Inspeção Industrial e Sanitária de Produtos de Origem Animal - RIISPOA. Diário Oficial da União: seção 1, Brasília, DF, p.3, 30 mar. 2017.

BRASIL. Ministério da Agricultura Pecuária e Abastecimento. Departamento de Inspeção de Produtos de Origem Animal. Instrução Normativa $\mathrm{n}^{\mathrm{o}} 76$, de 26 de novembro de 2018. Regulamentos Técnicos que fixam a identidade e as características de qualidade que devem apresentar o leite cru refrigerado, o leite pasteurizado e o leite pasteurizado tipo A. Diário Oficial da União: seção 1, Brasília, DF, p. 9, 30 nov. 2018.

CASSOLI, L. D.; MACHADO, P. F.; FREITAS, F. A. Diagnóstico de resíduos de antibióticos em amostras de leite provenientes de empresas com sistema de pagamento por qualidade na região Sudeste. Veterinária e Zootecnia, v. 20, n. 2, supl. 1, p. 88-89, 2013.

COSTA, M. A. et al. Fraude em leite cru refrigerado. Veterinária e Zootecnia, v. 20, n. 2, supl. 1, p. 42-43, 2013.

DUTRA, B. F. Avaliação físico-química e estudo retrospectivo das adulterações do leite cru em laticínio da região do Agreste pernambucano. 2010. 44 p. TCC (Medicina Veterinária) - Unidade Acadêmica de Garanhuns, Universidade Federal Rural de Pernambuco, Garanhuns, 2010.

FOOD AND AGRICULTURE ORGANIZATION OF THE UNITED NATIONS (FAO). Passerelle sur la production laitière et les produits laitiers. 2019a. Disponível em: http://www.fao.org/dairyproduction-products/dairy-productionproductsproduction/fr/. Acesso em: 29 mar. 2019.

FOOD AND AGRICULTURE ORGANIZATION OF THE UNITED NATIONS (FAO). Dairy Market Review. 2019b. 
Disponível em: http://www.fao.org/3/ ca3879en/ca3879en.pdf. Acesso em: 29 mar. 2019 .

FIRMINO, F. C. et al. Detecção de fraudes em leite cru dos tanques de expansão da região de rio Pomba, Minas Gerais. Revista do Instituto de Laticínios Cândido Tostes, v. 65, n. 376, p. $5-11,2010$.

FREITAS FILHO, J. R. et al. Caracterização físico-química e microbiológica do leite "in natura" comercializado informalmente no município de Garanhuns - PE. Revista Brasileira de Tecnologia Agroindustrial, v. 3, n. 02, p. 38-46, 2009.

INSTITUTO BRASILEIRO DE GEOGRAFIA E ESTATÍSTICA (IBGE). Indicadores IBGE - Estatística da Produção Pecuária, out.-dez. 2018. 2019. Disponível em: https://biblioteca.ibge.gov.br/visualizacao/ periodicos/2380/epp_2018_4tri.pdf. Acesso em: 29 mar. 2019.

IDEXX Laboratories. Thermo Fisher Scientific Inc. Disponível em: http://drinagh.com/ assets/docs/IDEXX-SNAP-Beta-Lactam-STTest.pdf. Acesso em: 13 dez. 2018.

MENDES, C. G. et al. Análises físicoquímicas e pesquisa de fraude no leite informal comercializado no município de Mossoró, RN. Ciência Animal Brasileira, v. 11, n. 2, p. 349-356, 2010.

MORAIS, C. M. Q. J. et al. Presença de resíduos de antibióticos em leite bovino pasteurizado. Ciência e Tecnologia de Alimentos, v. 30, supl. 1, p. 20-24, 2010.

MOTTA, R. G. et al. Indicadores de qualidade microbiológica, físico-química e detecção de resíduos de antimicrobianos no leite de vacas comercializado informalmente na região Sudeste do estado de São Paulo. Veterinária e Zootecnia. v. 20, n. 2, supl. 1, p. 116-117, 2013.

PE-AZ. Portal de Pernambuco. Agreste Meridional. 2016. Disponível em: http:// www.pe-az.com.br/o-estado/regioes/288agreste-meridional. Acesso em: 25 mar. 2019.

PEREIRA, M. N.; SCUSSEL, V. M. Resíduos de antimicrobianos em leite bovino: fonte de contaminação, impactos e controle. Revista de Ciências Agroveterinárias, v. 16, n. 2, p. 170-182, 2017.

PEZZA L. et al. Determinação simultânea de resíduos de cloranfenicol, tianfenicol e florfenicol em leite bovino por cromatografia eletrocinéticas micelar. Química Nova, v. 29, n. 5, p. 926-931, 2006.

SILVA, L. C. C. Capacidade de detecção de adulterações e suficiência das provas oficiais para assegurar a qualidade do leite pasteurizado. 2013. 99 p. Tese (Doutorado em Ciência Animal) - Universidade Estadual de Londrina, Londrina, 2013.

SILVA, H. O. et al. Adulteração do leite com adição de água por fornecedores de um laticínio do município de Conceição do Araguaia, estado do Pará, Brasil. Revista de Educação Continuada em Medicina Veterinária e Zootecnia do CRMV-SP, v. 14, n. 3, 2016.

SOUZA, L. B. et al. Resíduos de antimicrobianos em leite bovino cru no estado do Rio Grande do Norte. Ciência e Tecnologia de Alimentos, v. 18, 2017.

TRINDADE, L. C. A. et al. Qualidade de leite cru comercializado informalmente no município de Rio Pomba, MG. Higiene Alimentar, v. 32, n. 284-285, 2018. 